\title{
The human capital selection of young males seeking asylum in Germany
}

\author{
Martin Lange ${ }^{1 *+}$ (D) and Friedhelm Pfeiffer ${ }^{1,2^{*+}}$
}

\begin{abstract}
This study analyses the selection of a sample of 203 young male asylum seekers from Middle Eastern and African countries that recently arrived in Germany. The findings suggest that, on average, asylum seekers in our sample have $22 \%$ more years of schooling - the indicator used for human capital — when compared to same-aged males from their country of origin. In addition, the analysis suggests that asylum seekers in the sample often accumulated rather low or relatively high levels of schooling compared to same-aged males in their countries of origin. This phenomenon is even more pronounced for parental education. It is demonstrated that individual human capital influences short-run integration outcomes in Germany. The paper discusses potential economic explanations for the findings on immigrant selection and integration outcomes.
\end{abstract}

Keywords: Immigrant selection, Asylum seekers, Human capital, Family background, Integration

JEL Classification: F22, J15, J24

\section{Introduction}

Recent immigration of refugees from primarily Middle Eastern and African countries to Europe renewed concerns about the economic and social costs of humanitarian immigration. Evidence from previous refugee migration indicates that integration into the host economy and society often requires many years-although the overall impact on host countries seems to depend on a number of specific factors and the evidence is far from conclusive. ${ }^{1}$ One factor determining social costs and benefits is the selection of immigrants. The term 'selection' refers to a non-random group of persons emigrating from their home country. Do only the better educated or most able individuals flee from political terror and human rights abuse to distant countries, in order to find a better life? Or, is the recent cohort of refugees that arrived in Germany unaffected by this type of selectivity often found for labour market migrants ${ }^{2}$ and other refugees? ${ }^{3}$

\footnotetext{
*Correspondence: martin.lange@zew.de; friedhelm.pfeiffer@zew.de ${ }^{+}$Martin Lange and Friedhelm Pfeiffer contributed equally to the analysis and the writing of the article

${ }^{1}$ ZEW - Leibniz Centre for European Economic Research, P.O. Box 1034 43, 68034 Mannheim, Germany

Full list of author information is available at the end of the article
}

This study uses survey and administrative data from a sample of male asylum seekers ${ }^{4}$ from Middle Eastern and African countries that recently arrived in Germany,

\footnotetext{
${ }^{1}$ Cortes (2004) and Evans and Fitzgerald (2017), among others, find that refugees, after initial dependence on welfare, eventually become net fiscal contributors in the US; often surpassing assimilation outcomes of labour migrants. For Sweden, Hansen and Loftstrom (2003) and Lundborg (2013) find that refugees assimilate out of welfare at a faster rate than labour migrants, but do not reach the levels of the native population. Borjas and Monras (2017) argue that refugee flows may have significant distributional consequences adversely affecting the labour market opportunities of directly competing natives in the receiving countries. For a summary of the current debate on the economics of humanitarian migration see Dustmann et al. (2017).

${ }^{2}$ According to Chiswick (1999, p. 181) the "standard proposition in the migration literature is that migrants tend to be favorable self-selected for labor market success".

${ }^{3}$ Buber-Enser et al. (2016) show that refugees from the Middle-East to Austria have been positively selected in terms of education. Kondylis (2010) argues that the displaced Bosnian immigrants have been positively selected in terms of labour market outcomes. These findings also appear to be in line with studies of the Holocaust refugees (see Blum and Rei 2018; among others).

${ }^{4}$ The term 'asylum seeker' officially refers to a person who has applied for asylum, but has not yet received a decision on the application. We refer to the surveyed individuals in our study as asylum seekers because most of them belong to the group of asylum seekers as officially defined. See Sect. 2 for the data and sample description.
} 
in order to shed light on this question. We analyse the selection of a sample of 203 asylum seekers by assessing their relative position-and in addition, the position of their parents-in the distribution of human capital from the country of origin. By comparing individual years of schooling as an indicator of human capital to age-gender specific country of origin averages, we seek to deduce whether the asylum seekers in our sample are, on average, a positively or negatively selected group of the home country's population. In addition, we analyse the relevance of parental education to the selection of the asylum seekers-which is potentially particularly important for young emigrants. Parental education may indicate wealth and the degree of social ties, among other factors, and thus broaden the understanding of international migration and integration outcomes (Abramitzky et al. 2012; Borjas, 1993; Dustmann et al. 2012, among others).

Our contribution to the literature on the selection of asylum seekers is threefold. First, our study provides new evidence on the self-selection of international migrants by focusing on a group of recent young male humanitarian migrants, who dedicated months and a considerable amount of money to reach a safe country (see also Brücker et al. 2016; Buber-Ennser et al. 2016; Lange et al. 2017). Until now, studies which look at the self-selection of this group are rare. Data at the individual level in the home countries of asylum seekers is restricted, as humanitarian emigration is often the result of conflict or turmoil in the home country; where institutions providing data become deadlocked. In addition, economic considerations might not be the main driver of recent refugee emigration (among others, see Hatton 2016; Chin and Cortes 2015; or Docquier et al. 2017), which should reduce selfselection based on economic reasoning. However, there still seems to be a rather limited understanding on how these factors determine migration when it is not directed to neighbouring countries but to countries far away.

Our second contribution is the inclusion of parental background when studying selection among refugees for a sample of young males coming to Germany. The education of fathers and mothers contains complementary information on the socioeconomic background of asylum seekers and their socialisation. Parents likely play a role in migration decisions, particularly when refugees are relatively young, inexperienced, or have no savings. Parental background may also exert influences on integration in the host country. On the one hand, refugees who have better educated parents might have stronger ties to their home country, and therefore stronger motives for returning more promptly. In such cases their incentive to invest in host country specific skills may be lower. On the other hand, better educated parents could push their children to invest in integration within the host countries.
Our analysis shows that asylum seekers in our sample are, on average, positively selected with respect to our indicator of human capital; confirming Chiswick's (1999) hypothesis of a general positive selection of migrants, and the literature investigating earlier refugee waves. However, going beyond the average, we show that selection varies substantially among asylum seekers. There are considerable proportions of positively and negatively selected asylum seekers. We analyse Borjas' (1987) theory for the selection of international migrants to find an economic explanation for this observation. According to Borjas (1987), immigrants in destination countries with higher income inequality relative to their home country are positively selected, because they expect to profit from a higher income dispersion. Immigrants in destination countries with lower income inequality are negatively selected, because they aim to insure themselves against low incomes in the wage distribution. Preliminary findings indicate mixed evidence for this explanation. While Borjas' (1987) predictions do not explain the pattern observed in the distribution of individuals' education, it seems to be consistent with the observed pattern of parental years of schooling. Thus, depending on the indicator of human capital used, results differ.

Finally, we estimate the relevance of schooling acquired in the country of origin for short-term integration outcomes in Germany. Chiswick and Miller (2003) and Chiswick et al. (2005), among others, show that preimmigration schooling, work experience and skills are significant positive factors influencing earnings in the host country. Hartog and Zorlu (2009), however, present evidence that higher education of asylum seekers in their home countries does not translate into returns in the Dutch labour market (see also Sanromá et al. 2015; Fortin et al. 2016). We provide an empirical analysis of this question using data on host country language proficiency and employment. Results suggest that those asylum seekers in the sample who acquired more years of schooling perform better on a German language test, and in finding employment. For every additional year of home country schooling, the number of words increases by 0.62 and the probability of being employed by $13 \%$. Parental education does not seem to influence language acquisition or the probability of finding employment. For a third measure of human capital-work experience in the country of origin-we find no statistically significant effect on integration outcomes.

The study continues as follows. The next section introduces the data on newly arrived young male asylum seekers and presents descriptive statistics on the indicators of human capital. In Sect. 3, we analyse how the asylum seekers are selected in terms of individual and parental education, and discuss the relevance of socioeconomic 
explanations to better understand these findings. We then investigate the relevance of asylum seekers' schooling and their parents' educational background for integration outcomes in Germany in Sect. 4, and conclude in Sect. 5 .

\section{Survey data on newly-arrived asylum seekers}

Europe, and in particular Germany, saw a substantial increase in applications for asylum from 2014 to 2016. In 2015 alone, 890,000 persons, predominantly from Middle Eastern and African countries, immigrated to Germany in order to seek asylum (BMI 2016). In this study, we employ survey data from asylum seekers who were a part of this large influx to Germany in recent years. We utilize the "Real-World Laboratory Survey among Asylum Seekers (Reallabor Asyl)", which contains information on 370 asylum seekers living in two group accommodations close to the city of Heidelberg in Southern Germany. ${ }^{5}$ The data set contains items related to the socioeconomic status of the surveyed asylum seekers, both before and after they left their home countries, as well as information on short-term integration indicators such as German language proficiency and labour market participation. We rely utmost on the self-assessment of the interviewees' and their parents' educational attainment. We retrieve years of schooling from the response to the following question: "How many years did you go to school? (If applicable, including university)", ${ }^{6}$ for the asylum seeker as well as for the father and the mother. An advantage of using years of schooling for our study is its availability for most countries [see Barro and Lee (2013), among others]. To the best of our knowledge, our analysis is currently the only study which utilizes microdata on years of schooling of recent asylum seekers and their parents to explore selection patterns and refugee outcomes in the host country.

We restrict the sample on two dimensions. First, we omit asylum seekers from European sending countries, due to an exceptionally low probability of recognition as a refugee. Secondly, we do not consider female asylum seekers due to the very small sample size (8 respondents),

\footnotetext{
5 The survey was conducted in cooperation with the administration of these group accommodations and the local foreigner's administration offices in August/September 2016. Participation in the survey was voluntary and addressed all persons living in the accommodations. The computer-assisted interviews were performed at the group accommodations by professional native speaking interviewers. The aim was to cover the most frequently spoken languages such as Arabic, Dari/Farsi, Tigrinya, Pashtu, English, and German. The survey was complemented with information on asylum seekers' time in Germany and their asylum status from the local foreigner's administration office. For details on the survey, see Deger et al. (2017).

6 There is no further information on the curriculum, the length of a school day or year, nor any other quality dimension of schooling. However, schooling should still be an adequate measure of human capital as it fosters competencies generally linked to investments in human capital.
}

and their arguably different migration decisions and educational attainment in the home country. In addition, we disregard observations with missing information on own or parental years of schooling. ${ }^{7}$ The remaining sample contains 203 non-European male survey respondents (see Table 5 in Appendix for a summary of the sample selection procedure). Our sample covers several source countries in the Middle East and Africa. Almost 43\% of the asylum seekers in our sample originate from Afghanistan, $20.7 \%$ from Syria, and $18.2 \%$ from Iraq, which is in line with Buber-Ennser et al. (2016). Gambians constitute the largest group of African asylum seekers in our sample (10.3\%). The remaining 7.8\% stem from other Middle Eastern or African countries. ${ }^{8}$ Although the distribution of sending countries is not representative of the latest influx of asylum seekers in Germany, our sample covers the main countries of origin. ${ }^{9}$

Table 1 presents descriptive statistics on the characteristics of asylum seekers in the Reallabor Asyl sample. In addition, we compare these statistics with the IABBAMF-SOEP survey, a representative survey of asylum seekers in Germany (see Brücker et al. 2016, for more information). The first and third column show means, the second and fourth column present standard deviations. This comparison emphasizes that our sample of analysis is not representative of refugees in Germany. That is mainly due to two reasons. First, we focus on asylum seekers hosted in one region in Germany. Secondly, we focus on the share of recently arrived young working-age male asylum seekers. In addition, according to BAMF (2017), 47\% of the asylum seekers who applied for asylum in 2016 were in the age group 18-34, and more than $70 \%$ of them were male. In our sample of male asylum seekers, $91 \%$ are in this age group. Table 1 shows that the average age in the Reallabor Asyl sample is 24.87 years, with the youngest persons of age 18, which was the legal requirement to participate in the survey. Compared to the IABBAMF-SOEP, the average age of our sample is 8.18 years lower. At the time the survey was conducted, surveyed asylum seekers had lived in Germany for 10.6 months on average, indicating that they predominantly arrived at the

\footnotetext{
${ }^{7}$ Alternatively, based on a random regression imputation, missing years of schooling for fathers and mothers were replaced with their predictions and a random component drawn from a normal distribution with the standard deviation equal to the variance of the residual of the imputation regression (see Little and Rubin 2002). Results are quantitatively and qualitatively equivalent and therefore not discussed in the paper. They are available upon request from the corresponding author.

8 These are Iran, Algeria, Niger, Turkey, Pakistan and Tajikistan. See Table 6 in Appendix.

9 According to official data from BAMF (2017), the top three countries of origin of asylum applicants in 2016 are Syria (36.9\%), followed by Afghani$\operatorname{stan}(17.6 \%)$, and Iraq (13.3\%).
} 
Table 1 Asylum seeker characteristics

\begin{tabular}{|c|c|c|c|c|}
\hline & \multicolumn{2}{|c|}{ Reallabor Asyl } & \multicolumn{2}{|c|}{$\begin{array}{l}\text { IAB-BAMF- } \\
\text { SOEP }\end{array}$} \\
\hline & Mean & SD & Mean & SD \\
\hline Age in years & 24.87 & 6.50 & 33.05 & 10.54 \\
\hline Time in Germany in months & $10.56^{\mathrm{a}}$ & 3.00 & $16.71^{d}$ & 6.56 \\
\hline Years of schooling (S) & 8.85 & 5.04 & 10.06 & 3.09 \\
\hline Years of schooling father $\left(S^{F}\right)$ & 5.86 & 5.91 & - & - \\
\hline Years of schooling mother $\left(S^{M}\right)$ & 3.79 & 5.22 & - & - \\
\hline Parental years of schooling $\left(S^{P}\right)$ & 6.41 & 5.96 & - & - \\
\hline Work in home country (yes: $1 ;$ no: 0 ) & 0.73 & 0.45 & 0.97 & 0.18 \\
\hline Work Experience (in years) & $5.51^{b}$ & 6.05 & 10.88 & 10.56 \\
\hline Number of words in language test & $15.48^{c}$ & 8.64 & - & - \\
\hline Work in Germany [1 yes; 0 no] & 0.09 & 0.28 & 0.12 & 0.32 \\
\hline N & 203 & & 1993 & \\
\hline
\end{tabular}

Sources: Real-world Laboratory Survey among Asylum Seekers (Reallabor Asyl) and IAB-BAMF-SOEP. The IAB-BAMF-SOEP sample is restricted equivalently to the Reallabor Asyl sample in order to focus on the group of adult male asylum seekers from the most recent immigration period. Accordingly, we do not consider European and female refugees, nor refugees who migrated before 2014 or who are under age 18

${ }^{\text {a }} \mathrm{N}=201 ;{ }^{b} \mathrm{~N}=198 ;{ }^{\mathrm{c}} \mathrm{N}=195 ;{ }^{\mathrm{d}} \mathrm{N}=1990$

end of 2015 when humanitarian immigration to Germany reached its current peak.

In terms of human capital, asylum seekers spent, on average, 8.85 years in education; a very similar figure to our pilot study based on 81 asylum seekers (Lange et al. 2017), and to the IAB-BAMF-SOEP (10.06 years). Other studies using information on the highest educational degree obtained or school attended report similar values on the educational attainment of asylum seekers who recently migrated to Europe (see Buber-Ennser et al. 2016 for Austria, and Rich 2016 for Germany). Despite the mean of almost 9 years of schooling, there is a substantial share of asylum seekers without any years of schooling in our sample (14\%). This is a common finding for developing countries (Hertz et al. 2007) and is also in line with other recent studies based on representative data. Brücker et al. (2016) and Rich (2016) report the share of asylum seekers without any schooling to be 9 and 7\%, respectively, while according to Buber-Ennser et al. (2016), the share with no or very little schooling is $14 \%$ in their data.

Asylum seekers may also have interrupted or terminated their education due to conflicts in their home countries [see for instance Shemyakina (2011), or Diwakar (2015)]. The observed years of schooling should therefore be seen as a lower bound measure of the educational potential which might have been realized without home country conflicts. In addition to years spent in the education system, $73 \%$ of asylum seekers reported that they have acquired work experience in their home countries. The average years of work experience amounts to 5.51 years in the overall sample, and 7.63 years for those with work experience only.

Fathers of the asylum seekers have accumulated, on average, 5.86 years of education. Thus, on average, asylum seekers acquired 50\% more schooling compared to their fathers-reflecting the expansion in education seen in most countries around the world [see Morrison and Murtin (2009); Barro and Lee (2013)]. Mothers have acquired less years of schooling than fathers (3.79 versus 5.86 years of education), a gap that is not unusual for the countries under investigation (Duflo 2012). We construct a further indicator, referred to as parental human capital, which corresponds to the maximum of fathers' and mothers' years of schooling. This variable is dominated by fathers' years of schooling. Nevertheless, for over $10 \%$ of our sample parental education exceeds fathers' years of schooling, implying more schooling of mothers than fathers. ${ }^{10}$ Since we are also interested in the socioeconomic selection of asylum seekers, we use parental education throughout our study as a measure of human capital of the households in which asylum seekers were raised. Individual and parental years of schooling exhibit a correlation of 0.45 in our sample. They thus cover different as well as related factors relevant for the selection of asylum seekers and their integration outcomes.

The third panel of Table 1 presents two measures of short-term integration outcomes. First, we rely on the results of a German language test taken during the interview, in order to assess the acquired German language proficiency of participants. Using the test as a measure of German language skills is particularly important in order to avoid individual misrepresentation, which seems to be common in self-assessed language measures (see Edele et al. 2015). The test was designed to be straightforward and focused on the verbalization of single words rather than assessing grammatical knowledge. Survey respondents were asked to name as many surrounding objects as possible in $1 \mathrm{~min}$ in German. The environment was identical for all respondents. On average, asylum seekers were able to name almost 16 surrounding objects. Secondly, we utilize responses to the question as to whether asylum seekers have worked in the last week. We hereby deliberately allow for any kind of employment such as full- and part-time work, internships or other work arrangements. Similar to the IAB-BAMF-SOEP and Lange et al. (2017), 9\% of asylum seekers self-reported as being active in gainful employment.

\footnotetext{
${ }^{10}$ Cases in which mothers exhibit more years of schooling are not driven by single countries of origin, see Table 10 in Appendix.
} 
Table 2 Asylum seeker, parental, and country of origin years of education

\begin{tabular}{|c|c|c|c|c|c|c|c|c|}
\hline & \multicolumn{2}{|c|}{$\begin{array}{l}\text { Average individual } \\
\text { schooling }(\bar{S})\end{array}$} & \multicolumn{2}{|c|}{$\begin{array}{l}\text { Average schooling of peers } \\
\text { in the country of origin }\left(\bar{S}_{o}\right)\end{array}$} & \multicolumn{2}{|c|}{$\begin{array}{l}\text { Average parental schooling } \\
\left(\bar{S}^{P}\right)\end{array}$} & \multicolumn{2}{|c|}{$\begin{array}{l}\text { Average schooling } \\
\text { of parent's peers } \\
\text { in the country of origin } \\
\left(\bar{S}_{o}^{P}\right)\end{array}$} \\
\hline & Mean & SD & Mean & p-value & Mean & SD & Mean & $p$-value \\
\hline Afghanistan & 7.52 & 5.42 & 6.61 & 0.12 & 5.28 & 5.65 & 3.59 & 0.01 \\
\hline Syria & 10.40 & 3.83 & 7.64 & 0.00 & 8.14 & 5.64 & 6.95 & 0.16 \\
\hline Iraq & 10.49 & 4.20 & 8.76 & 0.02 & 9.92 & 5.11 & 5.43 & 0.00 \\
\hline Gambia & 7.52 & 5.63 & 5.65 & 0.15 & 2.43 & 4.75 & 2.38 & 0.96 \\
\hline Others & 9.94 & 4.71 & 8.24 & 0.26 & 5.13 & 6.77 & 5.62 & 0.80 \\
\hline Total & 8.85 & 5.04 & 7.25 & 0.00 & 6.41 & 5.96 & 4.65 & 0.00 \\
\hline $\mathrm{N}$ & 203 & & 203 & & 203 & & 203 & \\
\hline
\end{tabular}

Source: 'Real-world Laboratory Survey among Asylum Seekers'. Data on average years of schooling in home countries have been calculated based on Barro and Lee (2013). p-values are based on a two-sided t-tests of differences in means between years of schooling of asylum seekers or their parents and their respective home country peers

\section{The selection of asylum seekers}

\subsection{Individual, parental, and source country years of schooling}

In this section, we analyse the selection patterns of the 203 newly arrived male asylum seekers in Germany. Selection is empirically assessed by comparing the individual years of schooling of asylum seekers with the average years of schooling of same-aged persons from the country of origin. Ideally, we would use individual administrative or representative survey data on years of education from the countries of origin. This information is, however, not available for the sending countries. We thus dwell on the second best data source which is accessible: Barro's and Lee's (2013) dataset on educational attainment around the world. Although this data set only supplies aggregate estimated information on years of schooling, its main advantage is the possibility to compute age-group-by-gender cells of years of education as of 2010 for almost all sending countries. ${ }^{11}$ Age groups are fine-grained by 5 year intervals. Since we know the age, gender, and country of origin of the asylum seekers in our sample, we are able to match each observation with the average years of schooling of their peers from their home country. Furthermore, we analyse whether educational selection of asylum seekers is already reflected in the educational attainment of their parents, compared to same-aged persons in the home country. ${ }^{12}$

\footnotetext{
${ }^{11}$ Barro and Lee (2013) assess the years of schooling by combining various data sources on educational attainment in a large number of countries around the world. Their data set unfortunately does not cover all asylum seeker sending countries. 26 asylum seekers from Eritrea, Palestine, Gabon, and Nigeria are excluded, since we were not able to acquire information on the years of schooling for these sending countries. See Table 5 in Appendix.

12 Since our data does not contain information on the age of the parents, nor whether the asylum seeker is the first or any other child of the parents, we approximate the age of the parents in order to compare their years of
}

Table 2 shows the mean and the standard deviation of the years of schooling of asylum seekers and their parents for the main countries of origin in our sample. In addition, it presents the average years of schooling for the home country equivalents of the asylum seekers and their parents, as well as the p-values of a two-sided t-test of statistical differences in means. On average, Syrians and Iraqis accumulated more than 10 years of schooling. Afghanis and Gambians spent considerably less time in the education system. On average, asylum seekers in our sample have $22 \%$ or 1.6 additional years of schooling than comparable-aged persons from their home countries. The average young male asylum seeker thus seems to be positively selected in terms of human capital. ${ }^{13}$ Furthermore, asylum seekers seem to originate on average from positively selected households. Their parents accumulate an additional 1.76 years of schooling than their sameaged nationals, a difference of $38 \%$, which is highly statistically significant.

Exploring the relationship between parents' and asylum seekers' education further, we classify asylum seekers by their own, as well as their parents', years of education in

\footnotetext{
Footnote 12 (continued)

schooling to same-aged nationals. Based on United Nation (2013) data on age at first birth for mothers, it is assumed that mothers are 25 years old when giving birth. In addition, data from United Nations (2001) suggests that fathers are, on average, 5 years older than mothers. Hence, it is assumed the age of fathers to be 30 years at birth of the survey respondent. Although the degree of educational selection of the parental households depends on the age-at-birth assumptions, variations in these assumptions do not change our results qualitatively. In any scenario presented in Table 8 parental households acquired on average more human capital than sameaged nationals.

13 Average positive selection does not seem to be a pure aggregation effect. It also holds for each home country separately, however, lacks statistical significance for countries of origin with few observations.
} 
Table 3 Asylum seeker and parental years of schooling relative to country of origin (\# obs.; \%)

\begin{tabular}{llll}
\hline & $S_{i} \geq S_{o}$ & $S_{i}<S_{o}$ & Total (row) \\
\hline$S_{i}^{P} \geq S_{0}^{P}$ & $90 ; 44 \% ;$ & $19 ; 9 \%$ & $109 ; 54 \%$ \\
$S_{i}^{P}<S_{0}^{P}$ & $46 ; 23 \%$ & $48 ; 24 \%$ & $94 ; 46 \%$ \\
Total (column) & $136 ; 67 \%$ & $67 ; 33 \%$ & $203 ; 100 \%$
\end{tabular}

Source: 'Real-world Laboratory Survey among Asylum Seekers' for data on individual and parental human capital. Average years of schooling for home countries have been calculated based on Barro and Lee (2013). $S_{i}$ corresponds to individual years of schooling of the asylum seeker, while $S_{i}^{P}$ refers to the maximum years of schooling of the parents. $S_{0}$ and $S_{o}^{P}$ refer to the average years of schooling of persons in the same age-group in the country of origin for asylum seekers and their parents, respectively

relation to the home country averages in four different categories. The first and second columns of Table 3 differentiate asylum seekers who have accumulated above average years of education from those who have accumulated below average years of schooling. The rows divide parents' education, where the first row refers to parents with above and the second row to parents with below average years of schooling.

If asylum seekers, as well as their parents, accumulated above average years of schooling, they should belong to the upper part of the skill distribution in the country of origin. Analogously, asylum seekers and parents with below average years of schooling will belong to the lower part of the skill distribution. If asylum seekers accumulated more than the average number of years of schooling, but their parents did not, this hints towards upward mobility. If asylum seekers accumulated less than the average number of years of schooling, but their parents did not, this indicates a social decline (for instance, due to disrupted educational biographies from the start of violent conflicts in the home country).

In total, two thirds of asylum seekers are positively selected in terms of their own education. Yet, they stem from households with above or below average human capital in almost equal proportions. Given this finding, there seems to be a considerable number of asylum seekers who were on an upward trajectory even before fleeing their home country. The cell in the second row of the first column in Table 3 supports this notion, with 23\% of asylum seekers belonging to this category. On the contrary, asylum seekers experiencing downward social mobility make up only $9 \%$ of our sample. Furthermore, $44 \%$ of our sample have above average own education, and come from above average educated households. One third of asylum seekers are negatively selected, whereas $24 \%$ come from below average educated households and they themselves have a below average education.
The findings with regards to the positive selection of our sample of asylum seekers is consistent with Chiswick's (1999, p. 181) "standard proposition in the migration literature"; that immigrants are a positive selection of the home country's population. According to his study, predominantly the more capable strive for economic progress, and thus migrate to countries with better perceived economic opportunities net of migration costs. Although this proposition was originally developed for labour migrants, our results suggest that it also holds, on average, for our sample of internationally mobile humanitarian migrants.

\subsection{Selection of asylum seekers from their home countries} In this section, we investigate the distributional properties of the selection of asylum seekers. To do so, we calculate the differences between asylum seekers' years of schooling and the mean years of schooling of same-aged persons from their home countries: $\Delta S_{i}=S_{i}-S_{o}$. The advantage of this measure is that it centres non-selection at zero, allowing for direct interpretation. Negative values denote below average human capital, and positive values above average human capital. We also calculate this difference for the parents of asylum seekers, in order to analyse whether asylum seekers stem from households with above or below average human capital of the parent population.

Panel (a) of Fig. 1 depicts the density estimates of $\Delta S_{i}$ for asylum seekers and Panel (b) of $\Delta S_{i}^{P}$ for their parents. ${ }^{14}$ The estimated densities show a double humpshaped pattern for asylum seekers. A local peak at approximately -6 indicates that a considerable number of asylum seekers have fewer years of schooling in comparison to the average of their peers. However, the mode of the distribution, the second local peak, lies at around 4 additional years of schooling. With four more years of schooling, these asylum seekers have accumulated 51\% more schooling than their average home country peers. Panel (b) illustrates the distribution of parental years of schooling, which again is double humped-shaped. Now, the mode of the distribution in the difference of years of schooling is below zero (at approximately -4 ). Many asylum seekers stem from low or very low educated households. Nonetheless, parents' average years of schooling are above the number for nationals in the same age group. A second local peak is located at around 6 years of schooling. Thus, a substantial number of asylum seekers stem from relatively highly educated parents.

\footnotetext{
${ }^{14}$ The figures display the Epanechnikov kernel density estimator with a bandwidth that minimizes the mean integrated squared error.
} 


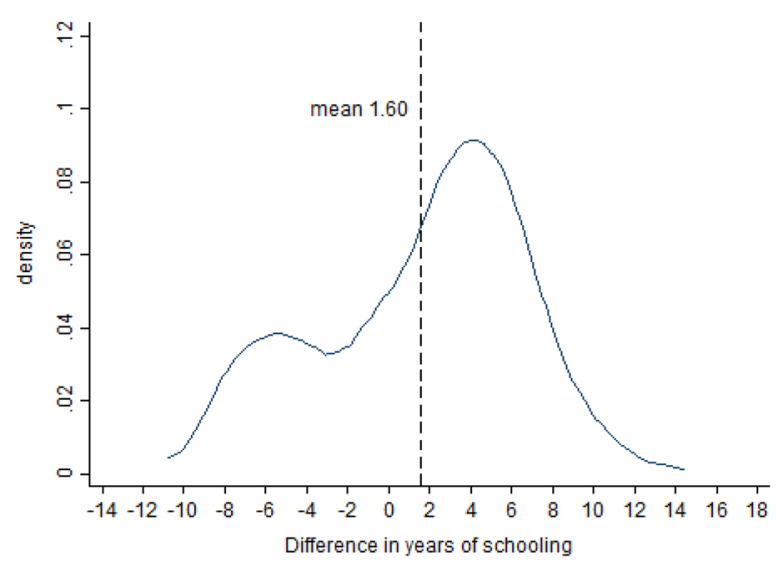

Panel (a): Asylum seekers

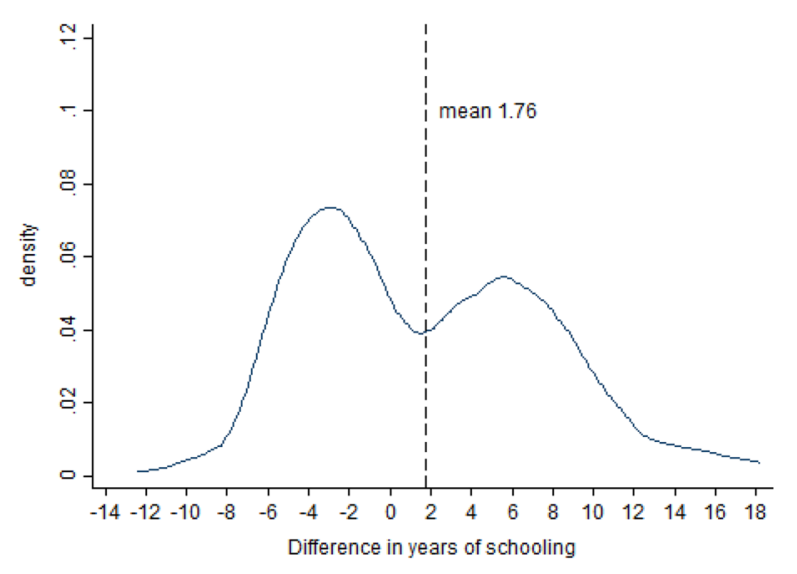

Panel (b): Parents

Fig. 1 Differences in years of schooling compared to the home country

Figure 1 suggests a bimodal distribution of the indicator for human capital of asylum seekers and-even more pronounced-of their parents. Thus, the patterns displayed in the figures seem to be at odds with the stylized normal unimodal distribution of immigrant selection [see Borjas (1987), Figure 1, p. 537]. The observed pattern in our sample may be the result of two effects. First, the group of asylum seekers might be divided into two subgroups: one group being a non-selected sample of the sending country population, fleeing their home country because of political persecution and/or violent conflicts not specifically related to our indicator of human capital. These persons presumably do not migrate primarily for economic reasons. If this group is merged with persons in our sample who may have migrated (also) for economic reasons, the selection pattern presented in Fig. 1 may occur.

Secondly, since asylum seekers stem from different source countries, Borjas' (1987) hypothesis on migrant selection might be helpful for explaining the observed distributional pattern. His model focuses not only on earnings differences, but in addition, on relative earnings distributions in the home and destination countries. It is argued that migrants with low human capital living in a country with relatively higher income inequality will choose to migrate to a destination country with relatively lower income inequality, a negatively selected group. Migrants with high human capital living in a country with relatively lower income inequality will choose to migrate to the destination country with relatively higher income inequality. This group would be positively selected. If sending countries differ in their income inequality relative to Germany, contrastingly selected groups of migrants might choose Germany as the destination country, leading to the observed pattern in Fig. 1.

In order to investigate whether Borjas' (1987) predictions apply to our findings, we establish whether asylum seekers in the sample stem from countries with more or less dispersed income distributions than seen in Germany. Relying on Gini coefficients of income inequality from the UNU-WIDER (2017) database, we compare income inequality of asylums seekers' home countries to Germany. Recent data on income inequality of sending countries is often not available, as such, we have to rely on Gini coefficients sometimes more than a decade old. According to the UNU-WIDER database, all sending countries exhibit income inequality higher than or similar to that of Germany (see Table 7 in Appendix). Countries with a similar Gini coefficient comprise Afghanistan, Syria, Iraq, Pakistan, and Tajikistan. Relating to Borjas (1987), we may predict that asylum seekers from these countries are neither positively nor negatively selected. For the other countries of origin, income inequality is higher than in Germany which should lead to a negative selection of immigrants according to this reasoning.

We once again construct density plots for the asylumseeker-home-country differences in years of schooling. Figure 2 presents the graphs for both groups of asylum seekers, where Panel (a) refers to the group of asylum seekers stemming from countries with similar income inequality, and Panel (b) for sending countries with higher income inequality. For Borjas' (1987) predictions to be applicable to our setting, Panel (a) should imply no selection on years of schooling among this group of asylum seekers, which is not the case. The mean difference is both positive and statistically significant. 


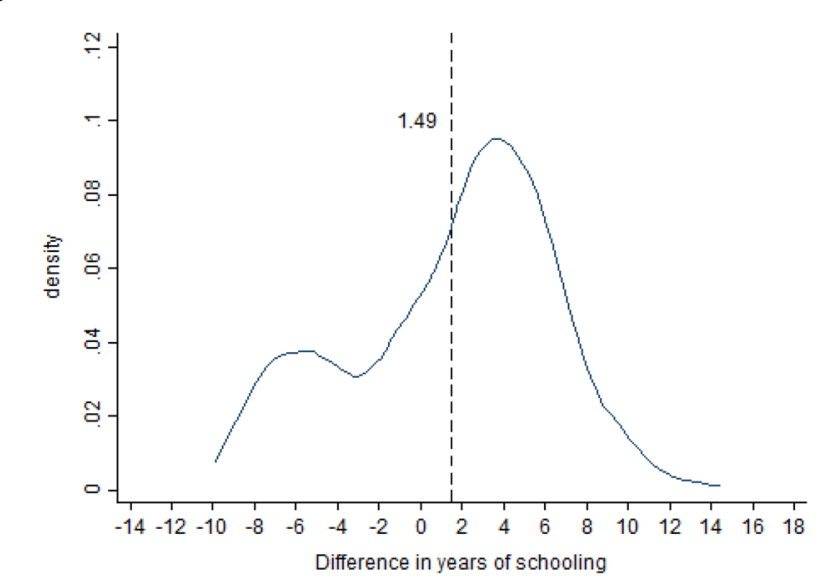

Panel (a): Home countries with similar ginis to Germany $(N=170)$

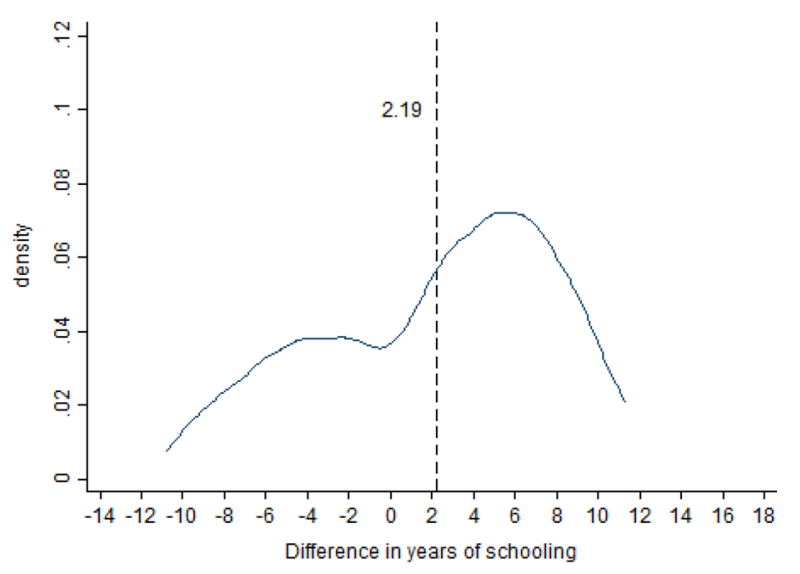

Panel (b): Home countries with higher ginis than Germany $(N=33)$

Fig. 2 Relative years of schooling by home country gini

Panel (b) should show predominantly a strong negative selection of asylum seekers, if Borjas' predictions were to be applicable to this group of asylum seekers. Yet, the mean difference is positive, and two thirds of the asylum seekers accumulated more years of schooling than comparable peers from their home countries. Figure 2 thus seems to indicate Borjas' (1987) explanation for the selection of labour migrants is not transferrable to our sample of asylum seekers.

However, when looking at parental years of schooling, Borjas' (1987) prediction on a negative selection seems to hold. Panel (b) of Fig. 3 illustrates that asylum seekers from countries with higher income inequality than Germany stem from households with below average human capital. Parental education might proxy otherwise unobserved factors of international migrant selection, particularly when migrants are young and parents are still quite influential, which is likely to be the case for our sample. Despite predominantly non-economic reasons, the observed pattern appears to be in line with economic explanations of labour migration if the parental human capital indicator is used.

We conclude that the selection of asylum seekers is probably due to a mix of economic as well as non-economic motivations for migration. On the one hand, push factors such as violent conflicts and human rights abuse are important drivers of international migration of asylum seekers-generating international migration flows of persons with presumably no specific economic reasons

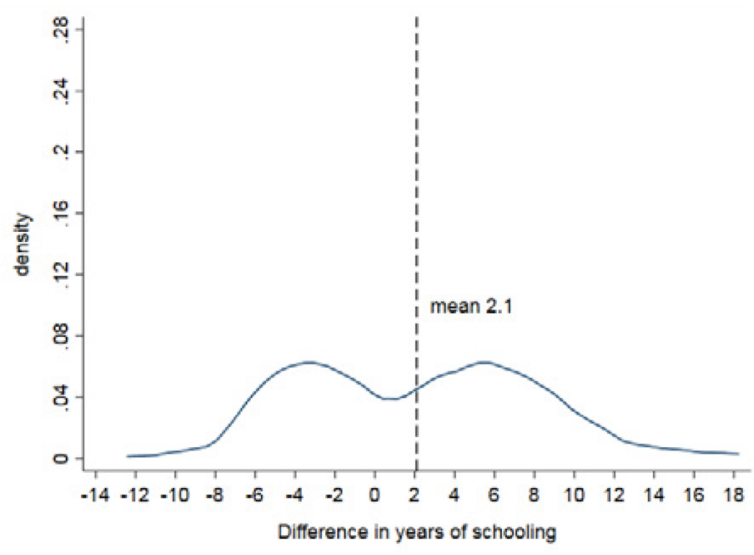

Panel (a): Similar Gini $(N=170)$

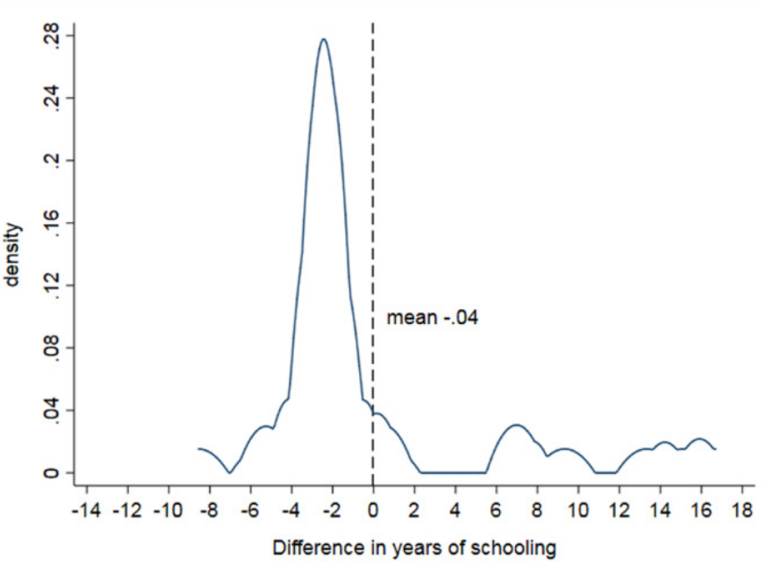

Panel (b): Higher Gini $(N=33)$

Fig. 3 Relative parental years of schooling by home country gini 
for emigration. On the other hand, asylum seekers who have to leave their home country may deliberately engage in migration to far-away countries, in search of higher economic gains. The analysis thus far hints at different conclusions with regard to the relevance of Borjas' ideas on international migrant selection for asylum seekers, depending on which measure of human capital is utilized.

\section{The role of human capital for short-term integration outcomes in Germany}

This section studies whether three indicators of human capital, individual and parental years of schooling and work experience in the home country, help to explain short-term integration outcomes in Germany. The dispersed human capital distribution might indicate that gaining labour market access could be differentially complicated for asylum seekers. Asylum seekers with higher levels of schooling may be more likely to achieve labour market access in the short-term, or to learn the German language faster. The general and potentially transferrable dimensions of human capital acquired during schooling may facilitate the adaption to a different language and employment culture. In addition, parental education might be an important factor influencing integration outcomes in Germany. It may signify otherwise unobserved factors, such as household wealth or social ties to the home country, which may foster or hinder integration.

The following equation is estimated in order to test the influence of human capital variables on these two outcomes:

$$
y_{i}=\alpha+\beta S_{i}+\text { rage }_{i}+\delta T_{i}+d_{c}+u_{i},
$$

where $y_{i}$ refers to the short-term integration outcomes for asylum seeker $i$. We use two different integration indicators. First, we employ the result of a German language test described in Sect. 2. Secondly, we utilize the information as to whether asylum seekers were employed within the week before the survey was conducted. $S_{i}$ denotes the years of schooling of the asylum seeker. In

\footnotetext{
${ }^{15}$ Since misreporting of time spent in Germany is common among asylum seekers, we rely on data from the local foreigner's administration offices on that matter. This information was not available for all asylum seekers in our sample. Due to an otherwise high number of missing values, we imputed the time in Germany for individuals with missing information based on a regression framework which regresses the individual time in Germany on the mean time in Germany of other asylum seekers from the same home country, country of origin dummies, the costs associated with the flight, whether the asylum seeker migrated with their family, and whether they crossed the Mediterranean. Excluding time in Germany as a variable, or running the analysis on the reduced sample, does not change the results quantitatively nor qualitatively. Regressions are available upon request from the corresponding author.

${ }^{16}$ It should be noted that we are not able to disentangle innate ability from years of education in the country of origin. Thus, our indicator of human capital should be interpreted as a proxy for the economic potential of asylum seekers.
}

some specification, we use parents' years of schooling $\left(S_{i}^{P}\right)$ as another measure of human capital. $T_{i}$ refers to the years spent in Germany until the day of the survey. ${ }^{15}$ Further control variables include age and country dummies $d_{c}$ for the most frequent countries of origin $c$ of asylum seekers (Afghanistan, Syria, and Iraq).

Table 4 summarizes the estimation results of the equation presented above. The first column of Table 4 shows the findings of a linear regression on the outcome of the German language test. Asylum seekers' years of schooling are statistically significantly related to German language skills. One additional year spent in the education system in the sending country increases the number of words in the test by 0.62 words. This corresponds, on average, to a $4 \%$ increase in the number of known German words per additional year of schooling. ${ }^{16}$ Furthermore, the estimation results suggest that the dominant factor in terms of effect size is the time spent in Germany. An additional year spent in Germany increases the number of words by 7.83, on average.

Column (2) in Table 4 presents the regression results including parental education instead of own education. The estimated coefficient of parental education is positive, but small and statistically insignificant. It seems that parental education is, at least in the short term, not an important driver of language acquisition. Parental education, as an indicator of human capital, might be rather country specific and works, among other channels, through local networks. Such 'soft' factors might become irrelevant in the host country.

Another way to investigate the influence of parental education is to look jointly at own and parental education of asylum seekers. In order to avoid running into a bad control problem of jointly including parental and own education in a single regression, we use the education groups as defined in Table 3. In column (3) of Table 4 we include a dummy variable for each of the parent-child education groups relative to the education in the country of origin, i.e. the group of upward mobile if $S_{i}>S_{o}$ and $S_{i}^{P}<S_{o}^{P}$, downward mobile if $S_{i}<S_{o}$ and $S_{i}^{P}>S_{o}^{P}$, and of asylum seekers and parents with below average home country education if $S_{i}<S_{o}$ and $S_{i}^{P}<S_{o}^{P}$. The reference group is asylum seekers with above average schooling whose parents also exhibit above average levels $\left(S_{i}>S_{o}\right.$ and $S_{i}^{P}>S_{o}^{P}$ ). The estimated coefficient of the group of upwardly mobile asylum seekers is statistically insignificant, although positive. Asylum seekers belonging to a group with below average education perform significantly worse than the reference group. Thus, we conclude that early language acquisition seems to be predominantly driven by own and not by parental education.

The fourth column of Table 4 reports the average marginal effects of a probit regression, with employment 
Table 4 Regression results for short-term integration outcomes

\begin{tabular}{|c|c|c|c|c|c|c|}
\hline & \multicolumn{3}{|c|}{ Number of words (OLS) } & \multicolumn{3}{|c|}{ Work in Germany (Probit) } \\
\hline & (1) & $(2)$ & (3) & (4) & (5) & (6) \\
\hline$S_{i}$ & $0.62^{* * *}(0.10)$ & - & - & $0.012^{* * *}(0.004)$ & - & - \\
\hline$S_{i}^{P}$ & - & $0.07(0.10)$ & - & - & $0.005(0.003)$ & - \\
\hline Upward mobile & - & - & $1.46(1.72)$ & - & - & $-0.027(0.051)$ \\
\hline Downward mobile & - & - & $-3.87^{* *}(1.84)$ & - & - & $-0.066(0.077)$ \\
\hline Low education & - & - & $-4.65^{* * *}(1.36)$ & - & - & $-0.144^{* *}(0.069)$ \\
\hline Age & $-0.16(0.11)$ & $-0.14(0.12)$ & $-0.13(0.12)$ & $0.003(0.003)$ & $0.004^{*}(0.003)$ & $0.004(0.004)$ \\
\hline Time in Germany & $7.83^{* * *}(2.79)$ & $8.01^{* * *}(2.60)$ & $7.81^{* * *}(2.76)$ & $-0.115(0.099)$ & $-0.089(0.100)$ & $-0.098(0.099)$ \\
\hline Constant & $1.23(4.00)$ & $5.38(4.17)$ & $7.06^{*}(4.08)$ & - & - & - \\
\hline Home country dummies & Yes & Yes & Yes & Yes & Yes & Yes \\
\hline Adj. R²/Ps. R & 0.23 & 0.11 & 0.19 & 0.10 & 0.06 & 0.09 \\
\hline N & 193 & 193 & 193 & 201 & 201 & 201 \\
\hline
\end{tabular}

Significance levels are indicated by $* \mathrm{p}<0.10,{ }^{* *} \mathrm{p}<0.05,{ }^{* * *} \mathrm{p}<0.01$. Robust standard errors are shown in parentheses. $S_{i}$ corresponds to individual years of schooling of the asylum seeker, while $S_{i}^{P}$ refers to the maximum years of schooling of the parents. Column (4) to (6) show marginal effects. The reference group for the education groups in column (3) and (6) is asylum seekers with above average own and parental years of schooling. Home country dummies consist of three largest countries of origin (Afghanistan, Syria, and Iraq). Source: 'Real-world Laboratory Survey among Asylum Seekers' for data on individual and parental years of schooling. Data on years of schooling in home countries are calculated from data based on Barro and Lee (2013)

status in Germany as the dependent variable. The dependent variable equals one if the asylum seeker had a paid job in the week prior to the interview and zero otherwise. The estimated coefficient of the individual years of schooling is both positive and statistically significant from zero. According to the reported average marginal effect, an additional year of schooling in the home country leads to a $1.2 \%$ point increase in the probability of finding a job in Germany. The magnitude is quite large, and corresponds to a $13 \%$ increase in the likelihood of being employed per additional year of home country education. As in the case of early language acquisition, the education of the parents does not seem to exert a major influence on early employment in Germany (see column (5)). The last column of Table 4 presents the results of a regression of having a job in Germany on the three human capital groups. We find no evidence that asylum seekers of any group outperform asylum seekers with above average years of schooling and above average educated parents. For negatively selected persons from households with below average human capital, we find on average a significant penalty of $14.4 \%$ points.

These findings demonstrate that years of schooling in the home country fosters integration outcomes in Germany-at least in the very short-term. Whether this also translates into long-term integration depends on a number of additional factors that we do not observe thus far [cf., for example, Hartog and Zorlu (2009) who find no long run influences of higher education for labour market success]. Our results suggest that the parental background, for which information is absent in most studies, has no influence on short-term integration outcomes.
In an alternative analysis, we include years of work experience in the home country as a third indicator of human capital in the estimation. The results are largely robust to that alteration (see Table 9 in Appendix). We thus conclude that work experience in the home country does not generate measurable additional gains for short-term integration outcomes, conditional on years of schooling and other control variables. Investments in work experience in the home country presumably are specific to the labour market of the home country, and may not produce significant returns in the substantially different economic and cultural environment in Germany.

\section{Conclusion}

In this study, the human capital selection of a sample of 203 young male asylum seekers from Middle Eastern and African countries now living in Germany is investigated. The main indicators of human capital used are individual and parental years of schooling in the country of origin. The selection on human capital is assessed relative to sameaged persons in their countries of origin. By including parental education, we aim to capture social and economic factors specific to the home country which are otherwise unobserved, and which should be informative for emigrant selection, particularly in the case of young migrants.

Our findings suggest that the asylum seekers under investigation have, on average, $22 \%$ more years of schooling than same-aged persons from their home countries; confirming positive self-selection. Notably, almost $16 \%$ have more than 12 years of schooling, which corresponds to the typical duration of high school in Germany. Almost $14 \%$ of asylum seekers in our sample 
have never been to school. A similar pattern is observed for parental education. Asylum seekers have relatively less or highly educated parents, suggesting that a substantial number of asylum seekers stem from poor households and from households of the upper class.

We find no clear evidence for Borjas' (1987) predictions on the selection of international migrants. While the prediction is not valid for individual years of schooling, it seems to be accurate for parental years of education. Asylum seekers in our sample from countries with higher income inequality than Germany stem, on average, from poorer parents.

Our findings furthermore hint at a mix of economic and non-economic reasons for emigration. On the one hand, civil war and violent conflicts might affect most groups in the sending country equally, leading to international migration across every part of the skill distribution. On the other hand, long distance international migration might be particularly costly, and thus more beneficial to persons from the upper end of the skill distribution; explaining the on average positive selection of asylum seekers from Middle Eastern and African countries.

Individual human capital seems to contribute to short-run integration outcomes in Germany. Regression results hint at statistically significant positive relationship between asylum seekers' schooling in the home country and the outcome of a language test as well as for the probability of finding work in Germany.

Although the asylum seekers examined are a positive selection of the home country's population, there is a substantial gap in their level of education compared to young Germans. Disregarding any concerns about the comparability of years of schooling between asylum seeker home countries and Germany, there is a difference of approximately 5 years of schooling. This gap is presumably partly the result of interrupted education biographies and, to an even larger extent, of less investment in schooling in the countries of origin. Still, despite an on average positive selection, the gap in education may constitute a major burden for integration outcomes. As a consequence, investments into specific further education and training opportunities for humanitarian migrants after their arrival in Germany should be considered as one dimension of integration policies. These investments need to be targeted individually, given the heterogeneity in the years of schooling from the home country-a challenging task for policy makers.

Our study sheds light on the human capital selection of a sample of recently arrived asylum seekers in Germany. The scope of our analysis is restricted to a sample of young males seeking asylum in one region in Germany and should be at best seen as a case study. Despite this limited scope, our findings may complement examinations of asylum seekers based on representative data. There are some further limitations that we are aware of. For one, we rely on aggregate, not individual, educational data from the countries of origin in order to assess emigrant selection. Furthermore, we utilize cross-sectional data of a small sample of countries of origin of male asylum seekers who have been living in Germany for 10 months, on average. The conclusions drawn in this study should thus be considered preliminary in nature.

\section{Acknowledgements \\ We thank the Ministry and Humboldt Foundation for their generous support, Sarra Ben Yahmed, Monika Gonser, Katrin Sommerfeld and Achim Wambach for fruitful discussions, participants of the Seminar in Labour and Welfare Economics at ZEW Mannheim, two anonymous referees and the editor for helpful comments, and Michael Kolb for excellent research assistance. The views expressed in this study are those of the authors, and do not necessarily reflect the views of the State Ministry. All errors are our own.}

\section{Authors' contributions}

Both authors read and approved the final manuscript.

\section{Funding}

This study was funded by Ministry of Science, Research and the Arts of Baden-Württemberg under grant number 8809-12/206/1 and the Humboldt Foundation.

\section{Availability of data}

The data have been collected by the authors during a research project which is a part of "Real-World Laboratory: Asylum Seekers in the Rhine-NeckarRegion" and can be accessed onsite at the ZEW - Leibniz Centre for European Economic Research in Mannheim.

Competing interests

The authors declare that they have no competing interests.

Author details

1 ZEW - Leibniz Centre for European Economic Research, P.O. Box 1034 43, 68034 Mannheim, Germany. ${ }^{2}$ University of Mannheim, Mannheim, Germany.

\section{Appendix}

See Tables 5, 6, 7, 8, 9, 10.

Table 5 Sequential sample reduction by selection criterion

\begin{tabular}{lc}
\hline & Sample size \\
\hline Number of observations & 370 \\
From Europe & 17 \\
Women & 5 \\
No information on individual schooling & 30 \\
No information on father's schooling & 78 \\
No information on mother's schooling & 8 \\
No information on individual age & 3 \\
No information on years of schooling in country of & 26 \\
$\quad$ origin & 203 \\
Total &
\end{tabular}

Source: 'Real-world Laboratory Survey among Asylum Seekers' 
Table 6 Number of observations by country of origin

\begin{tabular}{lc}
\hline Country & $\begin{array}{c}\text { \# observations } \\
\text { (share in \%) }\end{array}$ \\
\hline Afghanistan & $87(42.9)$ \\
Syria & $42(20.7)$ \\
Gambia & $21(10.3)$ \\
Iraq & $37(18.2)$ \\
Iran & $2(1.0)$ \\
Algeria & $4(2.0)$ \\
Niger & $2(1.0)$ \\
Turkey & $3(1.5)$ \\
Pakistan & $2(1.0)$ \\
Tajikistan & $2(1.0)$ \\
Total & $203(100)$ \\
\hline
\end{tabular}

Source: 'Real-world Laboratory Survey among Asylum Seekers'

Table 7 Ginis from world income inequality database (WIID)

\begin{tabular}{lll}
\hline Country & Gini & Year \\
\hline Afghanistan & 27.8 & 2008 \\
Syria & 32.0 & 2007 \\
Gambia & 47.0 & 2003 \\
Iraq & 30.9 & 2007 \\
Iran & 37.4 & 2013 \\
Algeria & 35.3 & 1995 \\
Niger & 34.0 & 2014 \\
Turkey & 40.2 & 2013 \\
Pakistan & 30.7 & 2013 \\
Tajikistan & 30.8 & 2014 \\
Germany & 30.1 & 2015 \\
\hline
\end{tabular}

Source: UNU-WIDER Database WIID3.4

Table 8 Parental years of schooling with alternative assumptions about parental age-at-birth

\begin{tabular}{llll}
\hline Assumption of parents age at birth of child & Father $\overline{\boldsymbol{S}}^{\boldsymbol{F}}$ & Mother $\overline{\boldsymbol{S}}^{\boldsymbol{M}}$ & Parents $\overline{\boldsymbol{S}}^{\boldsymbol{P}}$ \\
\hline 20 years older than child & 5.95 & 2.88 & 5.95 \\
25 years older than child & 5.40 & 2.37 & 5.40 \\
30 years older than child & 4.65 & 1.80 & 4.65 \\
35 years older than child & 4.10 & 1.42 & 4.10 \\
Average & 5.03 & 2.12 & 5.03 \\
$\mathrm{~N}$ & 203 & 203 & 203 \\
\hline
\end{tabular}

Source: 'Real-world Laboratory Survey among Asylum Seekers'. Average years of schooling in home countries have been calculated based on Barro and Lee (2013) 
Table 9 Further regression results for short-term integration outcomes

\begin{tabular}{|c|c|c|c|c|c|c|}
\hline & Number of $w$ & 5 (OLS) & & Work in Germa & robit) & \\
\hline & (1) & (2) & (3) & (4) & (5) & (6) \\
\hline$S_{i}$ & $0.65^{* * *}(0.11)$ & - & - & $0.013^{* * *}(0.004)$ & - & - \\
\hline$S_{i}^{P}$ & - & $0.06(0.11)$ & - & - & $0.006^{*}(0.003)$ & - \\
\hline Upward mobile & - & - & $1.09(1.74)$ & - & - & $-0.038(0.049)$ \\
\hline Downward mobile & - & - & $-4.32^{* *}(1.90)$ & - & - & $-0.071(0.076)$ \\
\hline Low Education & - & - & $-4.80^{* * *}(1.44)$ & - & - & $-0.154^{* *}(0.065)$ \\
\hline Work in Home Country & $1.43(1.68)$ & $2.24(1.80)$ & $2.02(1.74)$ & $-0.072(0.052)$ & $-0.073(0.053)$ & $-0.074(0.051)$ \\
\hline Work Experience & $0.02(0.20)$ & $-0.20(0.22)$ & $-0.07(0.21)$ & $0.003(0.006)$ & $0.003(0.005)$ & $0.004(0.006)$ \\
\hline Age & $-0.19(0.13)$ & $-0.05(0.14)$ & $-0.13(0.14)$ & $0.002(0.005)$ & $0.004(0.005)$ & $0.003(0.005)$ \\
\hline Time in Germany & $7.80^{* * *}(2.85)$ & $7.72^{* * *}(2.68)$ & $7.74^{* * *}(2.81)$ & $-0.120(0.105)$ & $-0.099(0.107)$ & $-0.094(0.105)$ \\
\hline Constant & $0.94(4.00)$ & $3.40(4.31)$ & $6.26(4.17)$ & - & - & - \\
\hline Home country dummies & Yes & Yes & Yes & Yes & Yes & Yes \\
\hline Adj. $R^{2} / P_{s} . R^{2}$ & 0.24 & 0.12 & 0.19 & 0.11 & 0.07 & 0.11 \\
\hline $\mathrm{N}$ & 188 & 188 & 188 & 196 & 196 & 196 \\
\hline
\end{tabular}

Significance levels are indicated by ${ }^{*} \mathrm{p}<0.10,{ }^{* *} \mathrm{p}<0.05,{ }^{* * *} \mathrm{p}<0.01$. Robust standard errors are shown in parentheses. $S_{i}$ corresponds to individual years of schooling of the asylum seeker, while $S_{i}^{P}$ refers to the maximum years of schooling of the parents. Column (4) to (6) show marginal effects. The reference group for the education groups in column (3) and (6) is asylum seekers with above average own and parental years of schooling. Home country dummies consist of three largest countries of origin (Afghanistan, Syria, and Iraq). Source: 'Real-world Laboratory Survey among Asylum Seekers' for data on individual and parental years of schooling. Data on years of schooling in home countries are calculated from data based on Barro and Lee (2013)

Table 10 Asylum seeker, parental and country of origin years of education for $S^{M}>S^{F}$

\begin{tabular}{|c|c|c|c|c|c|c|c|}
\hline & \multirow[t]{2}{*}{$\mathbf{N}$} & \multicolumn{2}{|c|}{ Average individual schooling $(S)$} & \multicolumn{2}{|c|}{ Average father's schooling $\left(S^{F}\right)$} & \multicolumn{2}{|c|}{$\begin{array}{l}\text { Average mother's } \\
\text { schooling }\left(S^{M}\right)\end{array}$} \\
\hline & & Mean & SD & Mean & SD & Mean & SD \\
\hline Afghanistan & 7 & 6.86 & 4.18 & 2.71 & 3.35 & 7.43 & 3.69 \\
\hline Syria & 7 & 12.57 & 2.76 & 6.57 & 5.86 & 10 & 4.73 \\
\hline Iraq & 6 & 12 & 2.53 & 5.67 & 6.35 & 12 & 4.20 \\
\hline Gambia & 2 & 8.5 & 6.36 & 1 & 1.41 & 9.5 & 9.19 \\
\hline Others & 0 & - & - & - & - & - & - \\
\hline Total & 22 & 10.2 & 4.17 & 4.59 & 5.17 & 9.68 & 4.66 \\
\hline
\end{tabular}

Source: 'Real-world Laboratory Survey among Asylum Seekers'. Data on average years of schooling in home countries have been calculated based on Barro and Lee (2013)

Received: 13 December 2018 Accepted: 29 May 2019

Published online: 06 June 2019

\section{References}

Abramitzky, R., Boustan, L.P., Eriksson, K.: Europe's tired, poor, huddled masses: self-selection and economic outcomes in the age of mass migration. Am. Econ. Rev. 102(5), 1832-1856 (2012)

BAMF: Das Bundesamt in Zahlen 2016-Modul Asyl. Bundesamt für Migration und Flüchtlinge, Berlin (2017)

Barro, R.J., Lee, J.W.: A new data set of educational attainment in the world, 1950-2010. J. Dev. Econ. 104(C), 184-198 (2013)

Blum, M., Rei, C.: Escaping Europe: health and human capital of Holocaust refugees. Eur. Rev. Econ. Hist. 22(1), 1-27 (2018)

BMI (2016). Bundesministerium des Inneren, Pressemitteilung: 890.000 Asylsuchende im Jahr 2015. Berlin

Borjas, G.J.: Self-selection and the earnings of immigrants. Am. Econ. Rev. 77(4), 531-553 (1987)
Borjas, G.J.: The intergenerational mobility of immigrants. J. Labour Econ. 11(1, Part 1), 113-135 (1993)

Borjas, G.J., Monras, J.: The labour market consequences of refugee supply shocks. Econ. Policy 32(91), 361-413 (2017)

Brücker, H., Rother, N., Schupp, J.: IAB-BAMF-SOEP-Befragung von Geflüchteten: Überblick und erste Ergebnisse, p. 116. Politikberatung kompakt, DIW Berlin (2016)

Buber-Ennser, I., Kohlenberger, J., Rengs, B., Al Zalak, Z., Goujon, A., Striessnig, E., Potancoková, M., Gisser, R., Testa, M.R., Lutz, W.: Human capital, values, and attitudes of persons seeking refuge in Austria in 2015. PLoS ONE 11(9), e0163481 (2016)

Chin, A., Cortes, K.E. (2015). The refugee/asylum seeker. In: Chiswick, B.R., Miller, P.W.(eds.) Handbook on the Economics of International Immigration, vol. 1, pp. 585-658

Chiswick, B.R.: Are immigrants favorably self-selected? Am. Econ. Rev. 89(2), 181-185 (1999)

Chiswick, B.R., Miller, P.W.: The complementarity of language and other human capital: immigrant earnings in Canada. Econ. Educ. Rev. 22(5), 469-480 (2003) 
Chiswick, B.R., Lee, Y.L., Miller, P.W.: Immigrant earnings: a longitudinal analysis. Rev. Income Wealth 51(4), 485-503 (2005)

Cortes, K.E.: Are refugees different from economic immigrants? Some empirical evidence on the heterogeneity of immigrant groups in the United States. Rev. Econ. Stat. 86(2), 465-480 (2004)

Deger, P., Gonser, M., Kolb, M., Kück, S., Lange, M., Mildenberger, G., Pfeiffer, F., Sommerfeld, K., West, C.: Integrationspotenziale: Ausgewählte Ergebnisse der Reallabor-Befragungen unter Geflüchteten. ZEW, Mannheim (2017)

Diwakar, V.: The effect of armed conflict on education: evidence from Iraq. J. Dev. Stud. 51(12), 1702-1718 (2015)

Docquier, F., Tansel, A., Turati, R.: Do Emigrants self-select along cultural traits? Evidence from the MENA Countries. In: IZA Working Papers, 11173 (2017)

Duflo, E.: Women empowerment and economic development. J. Econ. Lit 50(4), 1051-1079 (2012)

Dustmann, C., Frattini, T., Lanzara, G.: Educational achievement of secondgeneration immigrants: an international comparison. Econ. Policy 27(69), 143-185 (2012)

Dustmann, C., Fasani, F., Frattini, T., Minale, L., Schönberg, U.: On the economics and politics of refugee migration. Econ. Policy 32(91), 497-550 (2017)

Edele, A., Seuring, J., Kristen, C., Stanat, P.: Why bother with testing? The validity of immigrants' self-assessed language proficiency. Soc. Sci. Res. 52 , 99-123 (2015)

Evans, W.N., Fitzgerald, D.: The economic and social outcomes of refugees in the United States: evidence from the ACS. In: NBER Working Papers, No. 23498 (2017)

Fortin, N., Lemieux, T., Torres, J.: Foreign human capital and the earnings gap between immigrants and Canadian-born workers. Labour Econ. $41(\mathrm{C})$, 104-119 (2016)

Hansen, J., Lofstrom, M.: Immigrant assimilation and welfare participation. Do immigrants assimilate into or out of welfare? J. Hum. Resour. 38(1), 74-98 (2003)

Hartog, J., Zorlu, A.: How important is homeland education for refugees' economic position in The Netherlands? J. Popul. Econ. 22(1), 219-246 (2009)

Hatton, T.J.: Refugees, asylum seekers, and policy in OECD Countries. Am. Econ. Rev. 106(5), 441-445 (2016)

Hertz, T., Jayasundera, T., Piraino, P., Selcuk, S., Smith, N., Verashchagina, A.: The inheritance of educational inequality: international comparisons and fifty-year trends. BE J. Econ. Anal. Policy 7(2), 1-48 (2007)
Kondylis, F.: Conflict displacement and labor market outcomes in post-war Bosnia and Herzegovina. J. Dev. Econ. 93(2), 235-248 (2010)

Lange, M., Pfeiffer, F., van den Berg, G.J.: Integrating young male refugees: Initial evidence from an inclusive soccer project. J. Labour Market Res. (2017). https://doi.org/10.1186/s12651-017-0234-4

Little, R.J.A., Rubin, D.B.: Statistical analysis with missing data, 2nd edn. John Wiley \& Sons, Hoboken (2002)

Lundborg, P.: Refugees' employment integration in Sweden: cultural distance and labor market performance. Rev. Int. Econ. 21(2), 219-232 (2013)

Morrisson, C., Murtin, F.: The century of education. J. Hum. Capital 3(1), 1-42 (2009)

Rich, A. (2016). Asylerstantragsteller in Deutschland im Jahr 2015. Sozialstruktur, Qualifikationsniveau und Berufstätigkeit. Nürnberg: Forschungszentrum Migration, Integration und Asyl des Bundesamtes für Migration und Flüchtlinge

Sanromá, E., Ramos, R., Simón, H.: How relevant is the origin of human capital for immigrant wages? Evidence from Spain. J. Appl. Econ. 18(1), 149-172 (2015)

Shemyakina, O.: The effect of armed conflict on accumulation of schooling: results from Tajikistan. J. Dev. Econ. 95(2), 186-200 (2011)

United Nations, Department of Economic and Social Affairs, Population Division. World Marriage Patterns 2000. United Nations Publication (2001)

United Nations, Department of Economic and Social Affairs, Population Division. World Fertility Report 2012. United Nations Publication (2013)

UNU-WIDER: World income inequality database (WIID3.4). United Nations University, Helsinki (2017)

\section{Publisher's Note}

Springer Nature remains neutral with regard to jurisdictional claims in published maps and institutional affiliations.

\section{Submit your manuscript to a SpringerOpen ${ }^{\odot}$ journal and benefit from:}

- Convenient online submission

- Rigorous peer review

- Open access: articles freely available online

- High visibility within the field

- Retaining the copyright to your article

Submit your next manuscript at $\boldsymbol{\nabla}$ springeropen.com 